\title{
Delayed intervention with AGE inhibitors attenuates the progression of diabetes-accelerated atherosclerosis in diabetic apolipoprotein $\mathbf{E}$ knockout mice
}

\author{
A. M. D. Watson - A. Soro-Paavonen • K. Sheehy • J. Li • A. C. Calkin • A. Koitka • \\ S. N. Rajan - D. Brasacchio - T. J. Allen - M. E. Cooper • M. C. Thomas • \\ K. J. A. Jandeleit-Dahm
}

Received: 14 July 2010 /Accepted: 22 October 2010 /Published online: 14 December 2010

(C) Springer-Verlag 2010

\begin{abstract}
Aims/hypothesis Formation of AGEs is increased in the diabetic milieu, which contributes to accelerated atherogenesis. We studied whether delayed treatment with AGE-inhibiting compounds, alagebrium chloride and pyridoxamine dihydrochloride, affected established atherosclerosis in experimental diabetes in comparison with the angiotensin-converting enzyme inhibitor, quinapril.

Methods Streptozotocin-induced diabetic male Apoe $^{-/-}$ mice ( $n=24$ per group) received, by oral gavage, from week 10 to 20 of diabetes: no treatment; alagebrium $\left(1 \mathrm{mg} \mathrm{kg}{ }^{-1}\right.$ day $\left.^{-1}\right)$; pyridoxamine $(1 \mathrm{~g} / 1$ in drinking water);
\end{abstract}

A. M. D. Watson and A. Soro-Paavonen contributed equally to this study.

Electronic supplementary material The online version of this article (doi:10.1007/s00125-010-2000-9) contains supplementary material, which is available to authorised users.

A. M. D. Watson $\cdot$ A. Soro-Paavonen $\cdot$ K. Sheehy $\cdot$ J. Li $\cdot$

A. C. Calkin $\cdot$ A. Koitka $\cdot$ S. N. Rajan $\cdot$ D. Brasacchio $\cdot$

T. J. Allen $\cdot$ M. E. Cooper $\cdot$ M. C. Thomas $\cdot$

K. J. A. Jandeleit-Dahm $(\bowtie)$

Diabetes Division, Baker IDI Heart \& Diabetes Institute,

PO Box 6492, St Kilda Road Central,

Melbourne, VIC 8008, Australia

e-mail: Karin.Jandeleit-Dahm@bakeridi.edu.au

M. E. Cooper · K. J. A. Jandeleit-Dahm

Department of Medicine, Monash University,

Alfred Medical Research and Education Precinct (AMREP),

Commercial Road,

Melbourne, VIC, Australia

T. J. Allen $\cdot$ M. C. Thomas

Department of Epidemiology \& Preventive Medicine,

Monash University, The Alfred Centre,

Melbourne, VIC, Australia or quinapril (30 $\left.\mathrm{mg} \mathrm{kg}^{-1} \mathrm{day}^{-1}\right)$. Atherosclerotic lesion area (en face analysis) was evaluated for all groups.

Results Delayed intervention with alagebrium decreased plaque area in the diabetic Apoe $e^{-/-}$mice compared with untreated mice (total plaque area: alagebrium $10.6 \pm 1.6 \%$, untreated, $15.1 \pm 1.5 \%, p<0.05)$. This anti-atherosclerotic effect was comparable with that achieved with quinapril (quinapril $8.4 \pm 1.4 \%$, vs untreated, $p<0.05$ ). Pyridoxamine also attenuated plaque development in diabetic mice (5.7 \pm $1.2 \%$ vs untreated $11.9 \pm 1.1 \%, p<0.05)$. The antiatherosclerotic effect conferred by alagebrium and quinapril was associated with a significant reduction in vascular oxidative stress and circulating AGEs and methylglyoxal, although preformed AGEs were not removed from the vascular wall with either delayed intervention.

Conclusions/interpretation Inhibition of AGE accumulation, using a delayed intervention with alagebrium or pyridoxamine, significantly attenuated the progression of established diabetes-associated atherosclerosis, similar to results obtained with quinapril. These findings provide further evidence that blockade of AGE-mediated pathways may present a novel therapy for the prevention of atherosclerosis in diabetes.

Keywords ACE inhibition - Alagebrium - Atherosclerosis · Diabetes mellitus $\cdot$ Mouse model $\cdot$ Pyridoxamine

$\begin{array}{ll}\text { Abbreviations } \\ \text { ACE } & \text { Angiotensin-converting enzyme } \\ \text { AT1a } & \text { Angiotensin receptor type 1a } \\ \text { AT2 } & \text { Angiotensin receptor type 2 } \\ \text { GHb } & \text { Glycated haemoglobin } \\ \text { MCP-1 } & \text { Macrophage chemoattractant protein 1 } \\ \text { NHMRC } & \text { National Health and Medical Research Council }\end{array}$




\section{RAGE Receptor for AGEs}

RAS Renin-angiotensin system

SRAGE Soluble receptor for AGEs

VCAM1 Vascular cell adhesion molecule 1

\section{Introduction}

Diabetes is associated with accelerated development and progression of atherosclerosis, which contributes to the increased burden of cardiovascular disease in patients with diabetes. Although a number of different factors contribute to accelerated atherosclerosis in diabetes, recent data show that the accumulation of AGEs may have a significant role [1]. AGEs are post-translational modifications of proteins, DNA or lipids formed in vivo under the influence of carbonyl stress. AGE modifications have the potential to alter the structure and/or function of proteins, as well as to activate pro-atherogenic pathways including oxidative stress, inflammation [2] and the renin-angiotensin system (RAS) [3, 4].

In this study we explore the anti-atherosclerotic effect of two chemically different inhibitors of AGE accumulation, alagebrium chloride (ALT or ALT-711) and pyridoxamine in the diabetic apolipoprotein E knockout mouse $\left(\right.$ Apoe $\left.^{-/-}\right)$, a model of accelerated atherosclerosis [5-7]. Previous studies have shown that when given directly after the induction of diabetes, treatment with AGE inhibitors was able to attenuate atherosclerosis development [8]. It has been shown that diabetic Apoe $e^{-1-}$ mice with established atherosclerosis had decreased plaque area when treated with the decoy AGE receptor, soluble receptor for AGE (sRAGE) [5]. However, this is the only study to examine the effects of anti-atherosclerotic treatments for the secondary prevention of lesion development in the setting of established atherosclerosis.

Thus, in this study we aimed to examine whether alagebrium and pyridoxamine are able to attenuate the progression of atherosclerosis in animals with established diabetes-associated atherosclerosis and to compare these actions with that of the angiotensin-converting enzyme (ACE) inhibitor quinapril.

\section{Methods}

\section{Experimental model}

Male Apoe $e^{-/-}$mice (backcrossed 20 times to a C57BL/6 background; Animal Resource Centre, Canning Vale, WA, Australia) were rendered diabetic at the age of 6 weeks via five daily intraperitoneal injections of streptozotocin (Boehringer Ingelheim, Mannheim, Germany) $55 \mathrm{mg} \mathrm{kg}^{-1}$ day $^{-1}$, resulting in insulin deficiency [7]. After exposure to untreated diabetes for 10 weeks, mice ( $n=24$ per group) were randomised to receive, from 10 to 20 weeks after the induction of diabetes (weeks 16-26 of age), via daily oral gavage: (1) no treatment; (2) the anti-AGE agent alagebrium chloride (4,5-dimethyl-3-[2-oxo-2-phenylethyl]-thiazolium chloride; Synvista Therapeutics, Montvale, NJ, USA), $1 \mathrm{mg} \mathrm{kg}^{-1}$ day $^{-1}$; or (3) quinapril (Accupril; Pfizer Australia, West Ryde, NSW, Australia), $30 \mathrm{mg} \mathrm{kg}^{-1}$ day $^{-1}$. In addition, untreated control and diabetic animals were killed after 10 weeks diabetes in order to determine the plaque area at this stage. In a separate study this same protocol was used to treat animals with pyridoxamine (pyridoxamine dihydrochloride; BioStratum, Durham, North Carolina, USA), 1 g/l in drinking water.

The mice were housed at the Precinct Animal Centre, Baker Heart Research Institute, and studied according to National Health and Medical Research Council (NHMRC) guidelines after ethics approval from the Alfred Medical Research Precinct Animal Ethics Committee in line with international standards.

Mice were allowed access to standard mouse chow (Specialty Feeds, Glen Forrest, WA, Australia) and water ad libitum. Mice were killed using an intraperitoneal injection of Euthatal (100 mg/kg) (Delvet Limited, Seven Hills, NSW, Australia), followed by exsanguination by cardiac puncture. Excised aortas were placed in 10\% neutral buffered formalin and the lesion areas were quantified before the aortas were embedded in paraffin for immunohistochemical analysis. In a subset of animals, aortas were snap frozen in liquid nitrogen and stored at $-70^{\circ} \mathrm{C}$ for subsequent RNA extraction. At the conclusion of the study, glycated haemoglobin (GHb) was measured by highperformance liquid chromatography [9]. Total plasma cholesterol, HDL-cholesterol and triacylglycerol concentrations were measured in nine to ten mice per group using a standard commercial enzymatic assay using a Beckman Coulter LX20PRO Analyser (Beckman Coulter Diagnostics, Australia). LDL-cholesterol was calculated using the Friedewald formula.

\section{Plaque area}

The plaque area was quantified as described previously by Calkin et al. and Candido et al. [6, 7] In brief, aortas were cleaned of excess fat under a dissecting microscope and subsequently stained with Sudan IV-Herxheimer's solution (0.5\% wt/vol.) (Gurr; BDH, Poole, UK). Aortas were dissected longitudinally, divided into arch, thoracic, and abdominal segments, and pinned flat onto wax. Images were acquired with a dissecting microscope equipped with an Axiocam camera (Zeiss, Heidelberg, Germany). Total and segmental plaque areas were quantitated as a percentage area of aorta stained (Adobe Photoshop, version 7.0). 
Tissue was subsequently embedded in paraffin and sections cut for immunohistochemical analysis.

\section{Real-time RT-PCR}

Total RNA was extracted from whole aorta by homogenising (Polytron PT-MR2100; Kinematica, Littau-Lucerne, Switzerland) in Trizol (Life Technologies, Rockville, MD, USA). Total RNA was then DNAse-treated (DNA removal kit; Ambion, Austin, TX, USA) and cDNA was synthesised by reverse transcription (Pierce Biotechnology, Rockford, IL, USA). Quantitative real-time RT-PCR was performed using the Taqman System on an ABI Prism 7500 Sequence Detector (Applied Biosystems, Foster City, CA, USA) and analysed using a software detection system (SDS version 1.9) software. Gene expression was normalised to $18 \mathrm{~S}$ rRNA (Applied Biosystems). Detailed information on probes is provided in Electronic supplementary material (ESM) Table 1. For each analysis, nine to 13 animals per group were used.

\section{Immunohistochemistry}

Formalin-fixed paraffin sections of aortas prepared previously were used for trichrome staining (as per standard protocol), or were stained using antibodies: rabbit antinitrotyrosine (1:50; Chemicon, Temecula, CA, USA), goat anti-receptor for AGE (RAGE, 1:400; Biologo, Kiel, Germany); antibody against the macrophage marker F4/80 (rat anti-F4/80, 1:50; Abcam, Cambridge, UK); glycated serum albumin antibody $(1: 250$; kindly provided by $\mathrm{M}$. Coughlan, Diabetes Complications Division, Baker IDI Heart and Diabetes Institute, Melbourne, VIC, Australia); or rabbit anti-carboxymethyllysine (1:1,000 Abcam). AGEserum albumin antibody was pre-absorbed against BSA (Sigma-Aldrich, St Louis, MO, USA) for 30 min before use. Paraffin sections were dewaxed in xylene and hydrated. Slides were washed with distilled water and
Tris-buffered $\mathrm{NaCl}$ (TBS; $\mathrm{pH}$ 7.6). They were then incubated with $0.3 \%$ hydrogen peroxide in TBS for $20 \mathrm{~min}$. Subsequently, the slides were washed with distilled water and incubated with protein-blocking agent (LipshawImmunon, Pittsburg, PA, USA) or $0.5 \%$ skimmed milk powder in TBS for $30 \mathrm{~min}$. Additional blocking of endogenous avidin/biotin was used for nitrotyrosine staining (Avidin-Biotin Blocking Kit; Vector Laboratories, Burlingame, CA, USA). Sections were incubated with primary antibody prepared in TBS overnight at $4^{\circ} \mathrm{C}$. After washing (TBS and TBS+ Tween 20), slides were incubated with the appropriate biotinylated secondary antibody (Vector Laboratories, Burlingame, CA, USA) for $10 \mathrm{~min}$ at room temperature. Additionally, sections incubated with anti-F4/80 antibody were incubated in amplification reagent and strep-HRP (Dako catalysed signal amplification (CSA) kit; Dako North America, Carpinteria, CA, USA). All sections were then washed and stained with avidin-biotin horseradish peroxidase complex (Vectastain ABC Elite kit, Vector Laboratories). Positive staining was visualised with 3,3'-diaminobenzidine tetrahydrochloride (Sigma-Aldrich) and counterstained in Mayer's haematoxylin for $1 \mathrm{~min}$, followed by Scott's tap water for $15 \mathrm{~s}$. All experiments included negative control slides, in which the primary antibody had been omitted. Digital analysis of percentage of area stained (excluding adventitia) was performed as described previously by Soro-Paavonen et al. [10].

\section{Assessment of plasma AGE levels}

Plasma albumin fluorescence measurements were performed as described previously [11].

Plasma methylglyoxal measurements were performed using $20 \mu \mathrm{l}$ plasma samples which were diluted 1:5 with ammonium sulphate solution before adding chloroform (1:2 dilution). Samples were mixed, spun down and the resulting organic/aqueous interface precipitate removed by decanting the aqueous supernatant fraction. 5,6-Diamino-
Table 1 Metabolic variables of the groups at week 20

Data shown as means \pm SEM

${ }^{a}$ Performed in 24 animals per group

*** $p<0.001$ vs control Apoe $e^{-/-}$ group; ${ }^{\dagger} p<0.05$ vs diabetic Apoe ${ }^{-/-}$group; ${ }^{*} p<0.005$ vs diabetic Apoe $e^{-/-}$plus quinapril group

ALT, alagebrium

\begin{tabular}{|c|c|c|c|c|}
\hline \multirow[t]{2}{*}{ Variable } & \multicolumn{4}{|l|}{ Group } \\
\hline & Control & Diabetic & Diabetic/ALT & Diabetic/quinapril \\
\hline$n$ & 10 & 10 & 10 & 10 \\
\hline $\mathrm{GHb}(\%)^{\mathrm{a}}$ & $4.1 \pm 0.3$ & $15.3 \pm 0.8^{* * *}$ & $16.5 \pm 0.6^{* * *}$ & $17.7 \pm 0.7^{* * *}$ \\
\hline Plasma glucose $(\mathrm{mmol} / \mathrm{l})$ & $11.0 \pm 0.7$ & $29.0 \pm 1.4 * * *$ & $33.0 \pm 1.3 * * *$ & $31.4 \pm 2.6 * * *$ \\
\hline Body weight $(\mathrm{g})^{\mathrm{a}}$ & $31.0 \pm 0.4$ & $25.1 \pm 0.5^{* * *}$ & $23.0 \pm 0.4^{* * *}$ & $23.0 \pm 0.5^{* * *}$ \\
\hline Systolic blood pressure $(\mathrm{mmHg})$ & $124.0 \pm 1.8$ & $127.0 \pm 2.6$ & $120.9 \pm 1.5^{\ddagger}$ & $113.7 \pm 3.4^{\dagger}$ \\
\hline Total cholesterol $(\mathrm{mmol} / \mathrm{l})$ & $13.7 \pm 0.9$ & $23.0 \pm 2.0 * * *$ & $24.0 \pm 2.6^{* * *}$ & $28.1 \pm 3.5^{* * *}$ \\
\hline HDL-cholesterol (mmol/l) & $2.7 \pm 0.2$ & $3.0 \pm 0.3$ & $3.4 \pm 0.4$ & $4.6 \pm 0.7$ \\
\hline LDL-cholesterol (mmol/l) & $10.3 \pm 0.8$ & $19.0 \pm 1.9^{* * *}$ & $20.0 \pm 2.5^{* * *}$ & $23.1 \pm 3.0^{* * *}$ \\
\hline Triacylglycerol (mmol/l) & $1.7 \pm 0.2$ & $2.2 \pm 0.2$ & $1.6 \pm 0.2$ & $1.7 \pm 0.3$ \\
\hline
\end{tabular}


2,4-dihydroxypyrimidine sulphate (Sigma-Aldrich), $7 \mathrm{mmol} / \mathrm{l}$, was then added to the supernatant fraction before heating to $60^{\circ} \mathrm{C}$ for $60 \mathrm{~min}$, cooling in ice, then spinning again. The resulting reacted plasma solution was run through HPLC with a $10 \mathrm{nmol} / \mathrm{l}$ citrate buffer/methanol $(\mathrm{pH} 7.0)$ mobile phase, C18 stationary phase (Waters 'Atlantis' T3 $4.6 \times 150 \mathrm{~mm} 3 \mu \mathrm{m}$ column, Dublin, Ireland) with 330/500 nm excitation/emission at $25^{\circ} \mathrm{C}$ and methylglyoxal derivative eluting at $28 \mathrm{~min}$.

\section{Statistical analysis}

Data were analysed by ANOVA using SPSS 15.0 software. Post hoc comparisons were made among the various groups using Fisher's least significant difference method. Data are expressed as mean \pm SEM unless otherwise specified. $p<0.05$ was considered to be statistically significant.

\section{Results}

\section{Metabolic variables}

The induction of experimental diabetes was associated with significant increases in $\mathrm{GHb}$ and plasma glucose levels (Table 1). Untreated diabetic animals in the second study (delayed intervention treatment with pyridoxamine) also had significantly elevated levels of GHb compared with non-diabetic controls $(16.2 \pm 1.0[n=8]$ compared with $3.4 \pm$ $0.3 \%[n=8]$ respectively; $p<0.05)$. Treatment with alagebrium, quinapril (Table 1) or pyridoxamine (GHb 17.1 \pm $0.7 \%, n=7$ ) did not significantly affect glycaemic control in diabetic mice. Plasma concentrations of total cholesterol and LDL-cholesterol levels were also significantly higher in untreated diabetic animals (Table 1). These and other variables, such as body weight, were not significantly changed by alagebrium or quinapril treatment; however, delayed treatment with quinapril significantly decreased systolic blood pressure (Table 1).

\section{Plaque area}

Effect of delayed alagebrium or quinapril treatment Already after 10 weeks of diabetes, there was a significantly increased plaque area in diabetic compared with control $\mathrm{Apoe}^{-/-}$mice (total plaque area $3.1 \pm 0.3$ vs $0.7 \pm 0.2 \%$, compared with 0.7 $\pm 0.2 \%$ respectively; $p<0.05$ ) (Fig. 1a-d). After 20 weeks of diabetes, the plaque area had increased fivefold in diabetic animals (total plaque area $15.1 \pm 1.5 \%$ compared with $4.3 \pm$ $0.4 \%$ in non-diabetic controls) (Fig. 1). The diabetesassociated increase in plaque area was significantly attenuated in diabetic Apoe $^{-/-}$mice treated with alagebrium (10.7 \pm $1.6 \%$ total aortic plaque area) to a similar degree as that seen with quinapril treatment $(8.4 \pm 1.4 \%$ total plaque area $)$ a

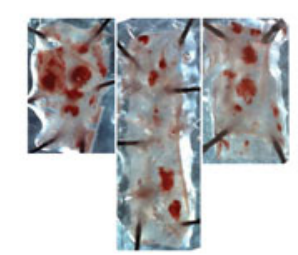

C
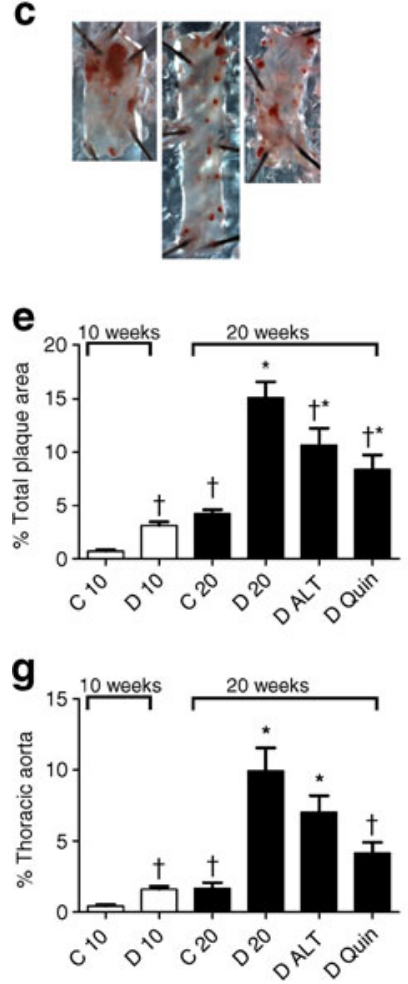

b

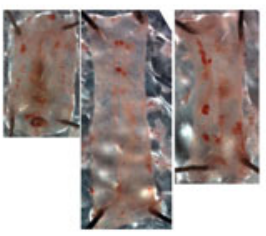

d

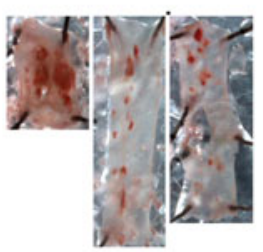

f

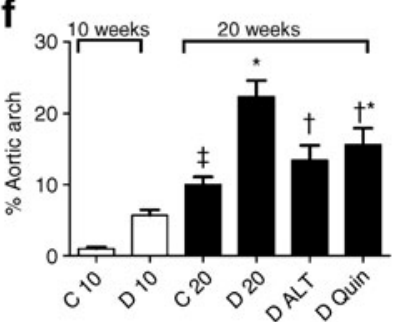

h

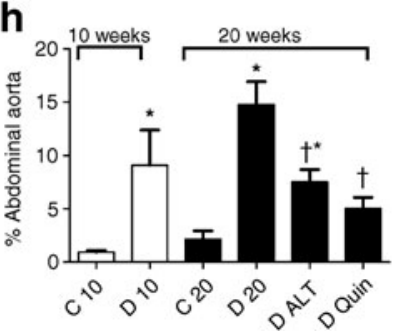

Fig. 1 a-d Representative photomicrographs of aortas at 20 weeks from: untreated diabetic mice (a); untreated non-diabetic control mice (b); diabetic mice+alagebrium $1 \mathrm{mg} / \mathrm{kg}$ for weeks 10-20 (c); diabetic mice+quinapril $30 \mathrm{mg} / \mathrm{kg}$ for weeks 10-20 (d). Lesions are shown in red after Sudan IV staining. $\mathbf{e}-\mathbf{h}$ Quantification of atherosclerotic plaque area $(\%)$ of aortic segments by the en face method in total aorta after 10 and 20 weeks of diabetes: (e) total aortic area; (f) aortic arch; (g) thoracic aorta; and (h) abdominal aorta. At 10 weeks $n=7-8$ per group, at 20 weeks $n=12-15$ per group. ${ }^{*} p<0.05$ vs duration-matched control mice at 10 and 20 weeks, ${ }^{\dagger} p<0.01$ vs diabetic untreated mice at 20 weeks, ${ }^{\star} p<0.05$ vs control mice at 10 weeks. In $\mathbf{g}, p=0.055$ for D 20 vs D alagebrium. C 10, control mice at 10 weeks; D 10, diabetic mice at 10 weeks; C 20, control mice at 20 weeks; D 20, diabetic mice at 20 weeks; D ALT, diabetic mice with alagebrium $1 \mathrm{mg} / \mathrm{kg}$ at 20 weeks; D Quinapril, diabetic mice+quinapril $30 \mathrm{mg} / \mathrm{kg}$ at 20 weeks

(Fig. 1). However, neither treatment fully arrested the progression of atherosclerosis when given as a delayed treatment from 10 to 20 weeks.

Effect of delayed pyridoxamine treatment In the second study, untreated diabetic Apoe $e^{-/-}$animals also had a significant increase in aortic plaque area after 20 weeks of diabetes (total plaque area $11.9 \pm 1.1 \%$ compared with $3.7 \pm$ $0.9 \%$ in non-diabetic controls; Fig. 2). Delayed intervention 
a

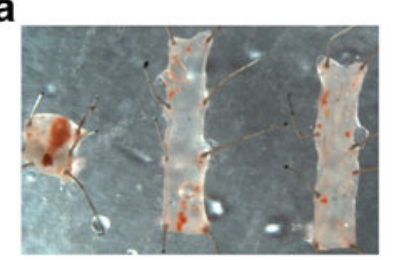

b

C
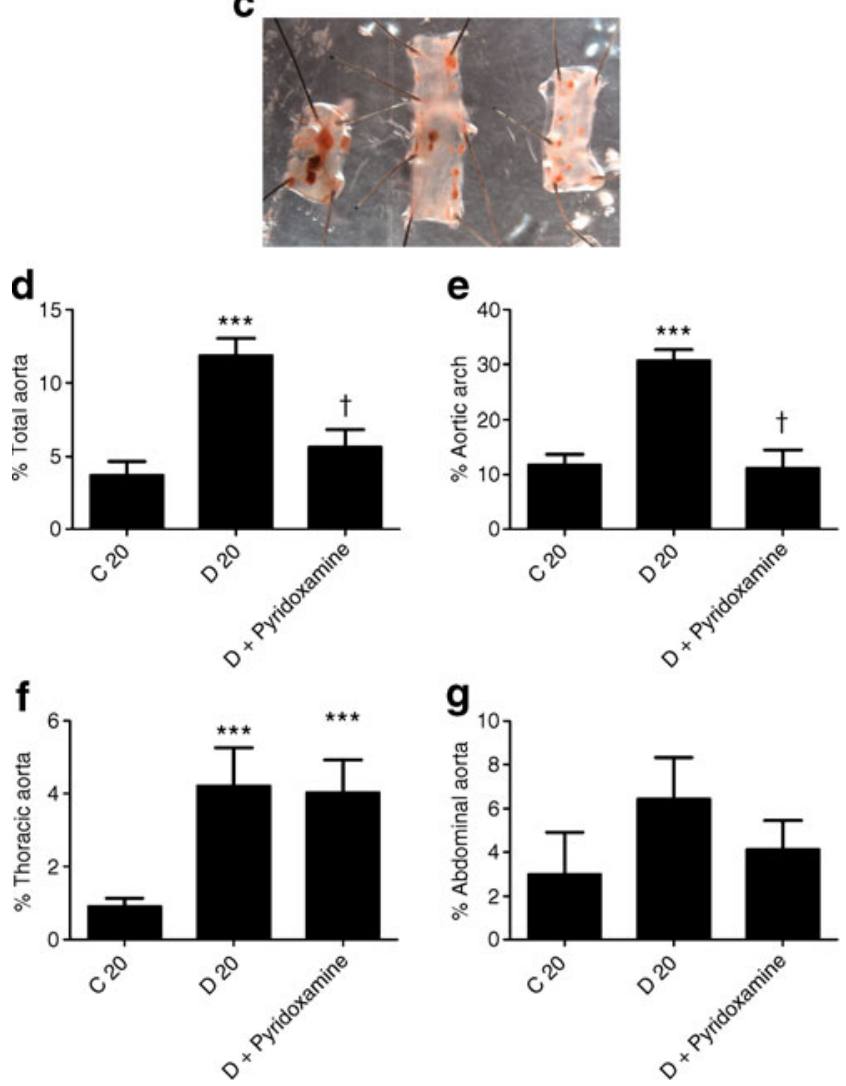

Fig. 2 a En face assessment of aortic plaque area in $A p o e^{-/-}$mice which were untreated non-diabetic control (a), untreated diabetic (b), or diabetic animals treated with pyridoxamine from week 10 to 20 of diabetes (c). $n=7-8$ per group. $\mathbf{d}-\mathbf{g}$ Percentage plaque area in: (d) total aortic area; (e) aortic arch; (f) thoracic aorta; and (g) abdominal aorta. Data shown as means \pm SEM. $* * * p<0.001$ vs control Apoe $e^{-/-}$group; ${ }^{\dagger} p<0.05$ vs diabetic Apoe $e^{-/-}$group. C 20, control mice at 20 weeks; D 20 , diabetic mice at 20 weeks; D + pyridoxamine, diabetic animals treated with pyridoxamine from week 10-20 of diabetes

with pyridoxamine significantly attenuated plaque progression in diabetic animals $(5.7 \pm 1.2 \%$ total plaque area; $p<$ $0.05)$. Similar to delayed treatment with alagebrium and quinapril, pyridoxamine did not arrest plaque development.

\section{AGE and RAGE}

Diabetes was associated with a significant increase in the fluorescent modification of circulating albumin (Fig. 3a), a widely used marker of AGE modification. When used as delayed interventions, both alagebrium and quinapril were associated with a reduction in circulating fluorescent albumin, being significant in the quinapril-treated group (Fig. 3a). Diabetes was also associated with a significant increase the AGE precursor methylglyoxal (Fig. 3b). The diabetes-associated increase in plasma concentrations of methylglyoxal was also reduced by treatment with alagebrium and quinapril, with alagebrium being significantly more effective in reducing methylglyoxal than quinapril treatment (Fig. 3b). The induction of diabetes was also associated with increased accumulation of AGEs in the vascular wall of $A p o e^{-/}$animals, as detected by a polyclonal anti-AGE antibody (ESM Fig. 1). However, when used as delayed interventions, alagebrium and quinapril failed to significantly reduce the tissue levels of pre-formed AGEs, including carboxymethyllysine (ESM Figs 1, 2).

Diabetic Apoe $^{--}$mice also showed significantly greater aortic expression of Ager, which encodes RAGE, and Cd36, which encodes the type B macrophage scavenger receptor CD36 antigen (Table 2). Aortic RAGE protein level, as assessed by immunostaining, was also significantly increased in diabetic Apoe $e^{-/-}$mice compared with non-
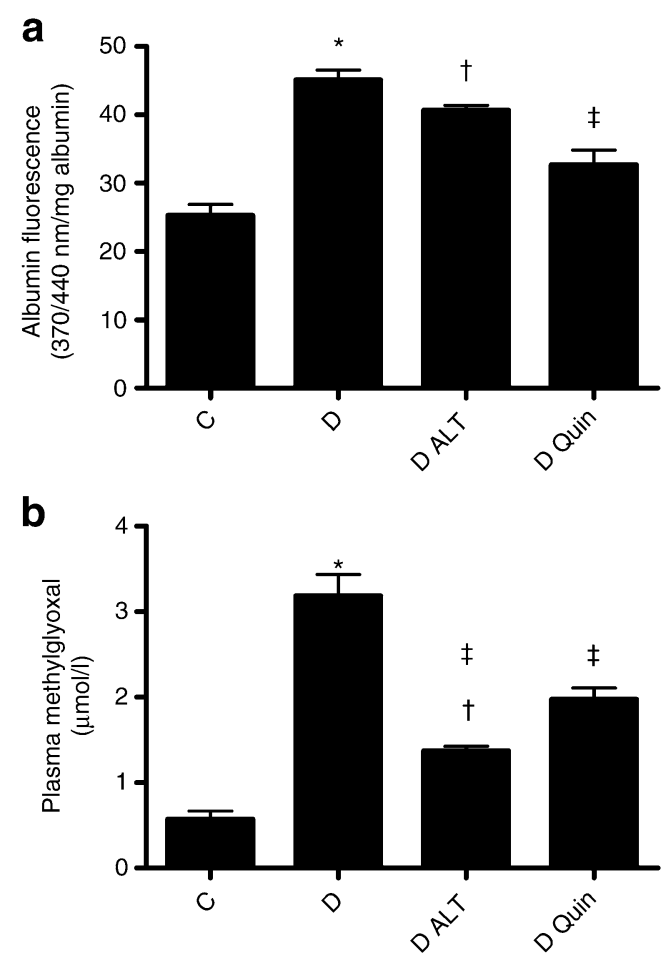

Fig. 3 (a) After 20 weeks significant increases in plasma albumin fluorescence $(370 / 440 \mathrm{~nm} / \mathrm{mg}$ albumin after 20 weeks, $n=6$ per group) and also (b) plasma methylglyoxal ( $n=4-7$ per group) were attenuated by quinapril and alagebrium treatment. Thus both treatments significantly decrease circulating levels of AGEs. ${ }^{*} p<0.05$ vs control mice; ${ }^{\dagger} p<0.05$ vs diabetic mice with delayed intervention with quinapril; ${ }^{\star} p$ $<0.05$ vs diabetic mice. C, non-diabetic control mice; D, diabetic mice; D ALT, diabetic mice with delayed intervention with alagebrium, $1 \mathrm{mg} / \mathrm{kg}$; D Quin, diabetic mice with delayed intervention with quinapril, $30 \mathrm{mg} / \mathrm{kg}$ 
Table 2 Gene expression of proatherogenic mediators in the aorta (current gene symbols in parentheses)
Data shown as means \pm SEM ${ }^{*} p<0.05$ vs control Apoe $e^{-/-}$ group; ${ }^{\dagger} p<0.05$ vs diabetic Apoe ${ }^{-/-}$group; ${ }^{*} p<0.05$ vs diabetic Apoe $e^{-/-}$plus quinapril group

${ }^{\mathrm{a}} p=0.060$ for diabetic vs diabetic plus alagebrium; ${ }^{\mathrm{b}} p=0.057$ for diabetic vs diabetic plus alagebrium

ALT, alagebrium

\begin{tabular}{|c|c|c|c|c|}
\hline \multirow[t]{2}{*}{ Variable } & \multicolumn{4}{|l|}{ Group } \\
\hline & Control & Diabetic & Diabetic/ALT & Diabetic/quinapril \\
\hline$n$ & 11 & 11 & 11 & 7 \\
\hline \multicolumn{5}{|c|}{ Markers of oxidative stress and RAS } \\
\hline p47phox $(N c f 1)$ & $1.0 \pm 0.2$ & $5.9 \pm 2.3^{*}$ & $3.4 \pm 0.3^{\ddagger \mathrm{a}}$ & $9.7 \pm 2.1 *$ \\
\hline gp91phox $(C y b b)$ & $1.0 \pm 0.3$ & $3.5 \pm 0.5^{*}$ & $3.6 \pm 0.6^{*}$ & $5.3 \pm 0.9^{* \dagger}$ \\
\hline AT1A $($ Agtrla $)$ & $1.0 \pm 0.2$ & $5.1 \pm 1.3^{*}$ & $1.2 \pm 0.3^{\dagger}$ & $1.2 \pm 0.4^{\dagger}$ \\
\hline AT2 (Agtr2) & $1.0 \pm 0.2$ & $5.6 \pm 0.9 *$ & $3.0 \pm 0.4^{* \dagger}$ & $3.0 \pm 0.4^{* \dagger}$ \\
\hline $\operatorname{ACE}($ Ace $)$ & $1.0 \pm 0.1$ & $2.9 \pm 0.6^{*}$ & $2.3 \pm 0.4 *$ & $2.4 \pm 0.7$ \\
\hline \multicolumn{5}{|c|}{ Mediators of inflammation and fibrosis } \\
\hline VCAM1 (Vcam1) & $1.0 \pm 0.2$ & $4.3 \pm 0.7^{*}$ & $3.3 \pm 0.5^{*}$ & $2.9 \pm 0.4^{* \dagger}$ \\
\hline $\mathrm{MCP}-1(\mathrm{Ccl})$ & $1.0 \pm 0.3$ & $6.4 \pm 1.3^{*}$ & $6.3 \pm 1.4^{*}$ & $6.8 \pm 1.3^{*}$ \\
\hline IL-1 $\beta(I l l b)$ & $1.0 \pm 0.3$ & $11.2 \pm 2.0^{*}$ & $6.7 \pm 1.0^{* \dagger}$ & $5.4 \pm 1.2^{* \dagger}$ \\
\hline \multicolumn{5}{|l|}{ AGE receptors } \\
\hline RAGE (Ager) & $1.0 \pm 0.1$ & $4.3 \pm 1.1^{*}$ & $2.4 \pm 0.4^{\mathrm{b}}$ & $2.5 \pm 0.7$ \\
\hline CD36 $(C d 36)$ & $1.0 \pm 0.2$ & $2.1 \pm 0.4^{*}$ & $1.4 \pm 0.3$ & $1.2 \pm 0.3$ \\
\hline
\end{tabular}

diabetic control animals (Fig. 4). Delayed intervention treatment with either alagebrium or quinapril failed to significantly affect $C d 36$ gene expression. Treatment with alagebrium tended to attenuate Ager expression $(p=0.057)$ (Table 2). Neither alagebrium nor quinapril treatment significantly attenuated RAGE protein levels (Fig. 4) when given as delayed intervention for 10 weeks.

Effect of delayed intervention with alagebrium or quinapril on vascular inflammation

Oxidative stress Expression of Ncfl, encoding NADPH oxidase subunits $\mathrm{p} 47 \mathrm{phox}$, and also of $C y b b$, encoding gp91phox, was upregulated in the diabetic vasculature (Table 2). Treatment with alagebrium did not affect $C y b b$ expression. However, there was significant attenuation of Ncfl expression when compared with quinapril-treated animals, but not untreated diabetic animals. Nitrotyrosine, an index of peroxynitrite-mediated tissue damage, was significantly increased in the aortas of untreated diabetic Apoe ${ }^{-/-}$mice when compared with non-diabetic control animals (Fig. 5). Treatment with both alagebrium and quinapril significantly ameliorated nitrotyrosine staining, suggesting that delayed intervention with both therapies was associated with decreased oxidative stress in the vasculature. Despite the increased gene expression of $C y b b$ observed with delayed intervention with quinapril, nitrotyrosine levels were reduced in the aorta, suggesting an overall reduction in oxidative stress with quinapril.

Inflammatory markers Diabetes was associated with an upregulation of the aortic gene expression for vascular cell adhesion molecule 1 (VCAM1), the pro-inflammatory marker and leucocyte adhesion molecule, as well as upregulation of expression of $\mathrm{Ccl}$, which encodes monocyte chemotactic protein 1 (MCP-1) (Table 2). Treatment with alagebrium did not significantly alter $V$ cam 1 or $\mathrm{Ccl} 2$ expression; however, delayed intervention with quinapril significantly attenuated $V$ cam 1 expression in diabetic animals. Staining for the macrophage marker F4/80 was increased in aortas of untreated diabetic mice compared with non-diabetic control mice; however, neither treatment significantly reduced F4/80 levels (ESM Fig. 3). Expression of $I l 1 b$, which encodes IL-1 $\beta$, a cytokine that increases adhesion factors on endothelial cells to enable transmigration of leucocytes, was highly upregulated in diabetic vascular tissue (Table 2). Treatment with both alagebrium and quinapril significantly reduced $I l 1 b$ expression in aortas from diabetic animals.

Vascular collagen content as assessed by trichrome staining was significantly increased in the aorta of diabetic animals (Fig. 6). Delayed intervention therapy with alagebrium significantly attenuated this increase in vascular collagen deposition, whereas treatment with quinapril did not have this effect.

\section{Renin-angiotensin system}

Reflecting an activated vascular renin-angiotensin system (RAS), diabetic Apoe $e^{-/-}$mice had a marked increase in expression of the gene for angiotensin II type 1a receptor (AT1a; Agtrla) and angiotensin II type 2 receptor (AT2; Agtr2). Treatment with both alagebrium and quinapril was associated with reduced expression of both these genes (Table 2). The expression of the gene encoding ACE was also upregulated by diabetes; however, neither treatment affected Ace expression. 
a

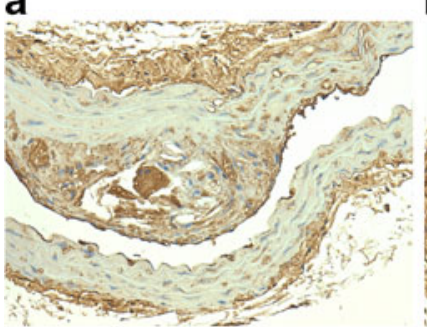

b

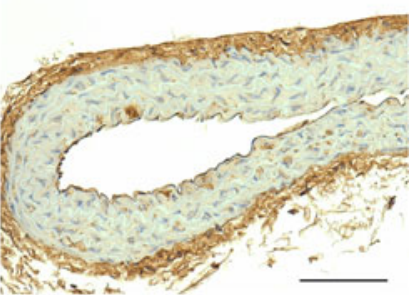

c

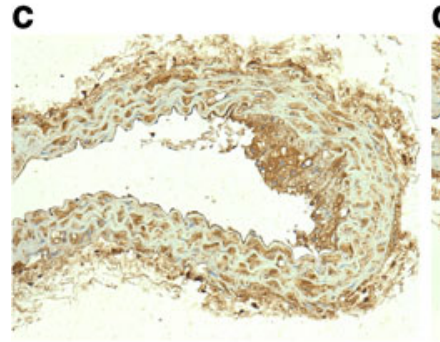

d
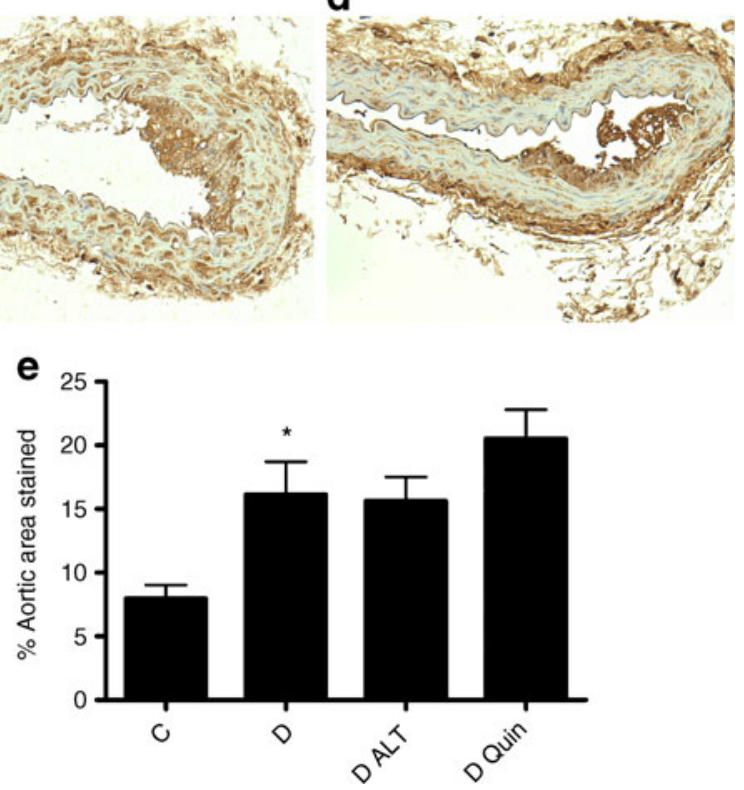

Fig. 4 a-d Photomicrographs of aorta from Apoe-knockout mice stained for RAGE: untreated diabetic mice (a); untreated non-diabetic control mice (b); diabetic mice + alagebrium, $1 \mathrm{mg} / \mathrm{kg}$, for weeks 10 20 (c); diabetic mice + quinapril $30 \mathrm{mg} / \mathrm{kg}$ for weeks $10-20$ (d). e Digital quantification of RAGE staining in the whole aorta $(n=7-8$ per group). Scale bar represents $100 \mu \mathrm{m}$. Data presented as means \pm SEM. ${ }^{*} p<0.05$ vs control animals. C, non-diabetic control mice; D, diabetic mice; D ALT, diabetic mice with delayed intervention with alagebrium, $1 \mathrm{mg} / \mathrm{kg}$; D Quin, diabetic mice with delayed intervention with quinapril, $30 \mathrm{mg} / \mathrm{kg}$

\section{Discussion}

Diabetes is associated with a significant increase in the size and complexity of the atherosclerotic plaque, contributing to increased cardiovascular events and premature mortality. Current treatment strategies attenuate, but do not prevent, cardiovascular complications and there remains an urgent need for new targets and interventions.

Prolonged hyperglycaemia, dyslipidaemia and oxidative stress in diabetes are associated with the production and accumulation of AGEs. AGEs are thought to directly contribute to the development and progression of cardiovascular disease in diabetes by promoting vascular dysfunction and injury, accelerating atherogenesis. As a result, novel therapeutic agents to reduce the accumulation of AGEs in diabetes have gained interest as potential cardioprotective approaches.

Clinically, it is more likely that diabetic patients will present with a certain degree of underlying atherosclerosis prior to the initiation of treatment. Indeed, cardiovascular disease is often silent in patients with diabetes. Most experimental studies, however, use a preventive treatment regimen, commencing therapies almost immediately after inducing diabetes. Studies using a delayed intervention protocol in established atherosclerosis are rare, with the exception of studies described for sRAGE [5].

Our group has previously demonstrated a significant reduction of atherosclerosis with alagebrium treatment in diabetic Apoe $^{-/-}$mice when given as a preventive therapy, a $\quad$ b

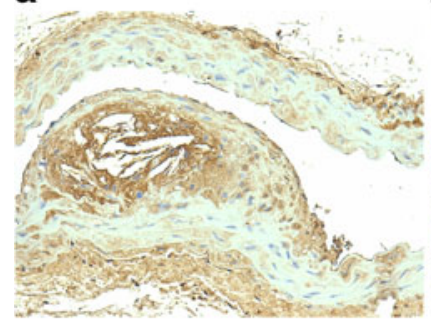

b

C
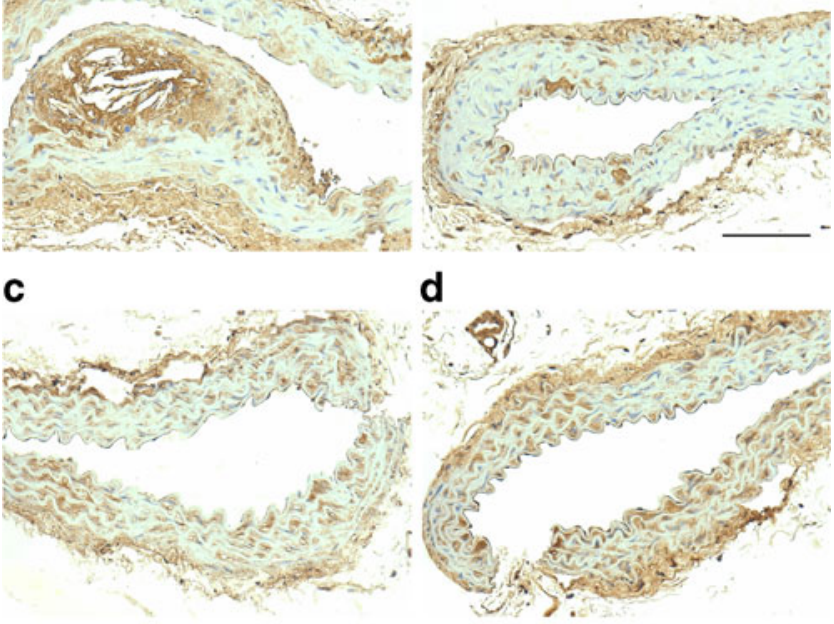

d
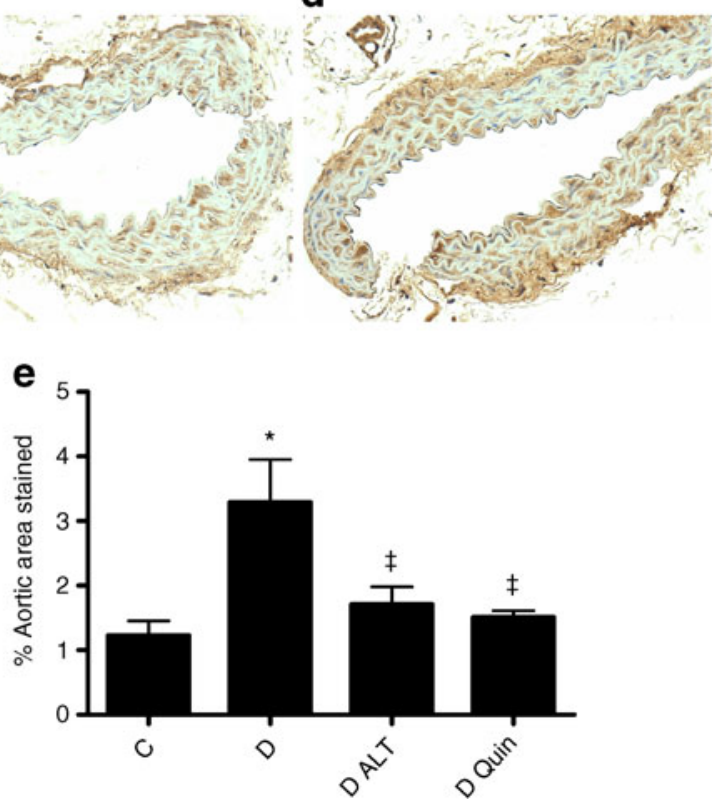

Fig. 5 a-d Photomicrographs of mouse aorta stained for a marker of oxidative stress, nitrotyrosine: untreated diabetic mice (a); untreated non-diabetic control mice (b); diabetic mice+alagebrium, $1 \mathrm{mg} / \mathrm{kg}$, for weeks 10-20 (c); diabetic mice+quinapril $30 \mathrm{mg} / \mathrm{kg}$ for weeks $10-20$ (d). e Digital quantification of nitrotyrosine staining in the whole aorta ( $n=5-8$ per group). Scale bar represents $100 \mu \mathrm{m} .{ }^{*} p<0.05$ vs control mice; ${ }^{*} p<0.05$ vs diabetic mice. C, non-diabetic control mice; D, diabetic mice; D ALT, diabetic mice with delayed intervention with alagebrium, $1 \mathrm{mg} / \mathrm{kg}$; D Quin, diabetic with delayed intervention with quinapril, $30 \mathrm{mg} / \mathrm{kg}$ 
a

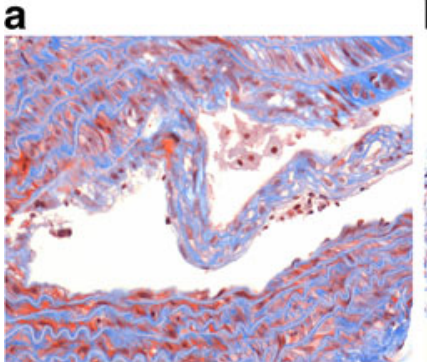

b

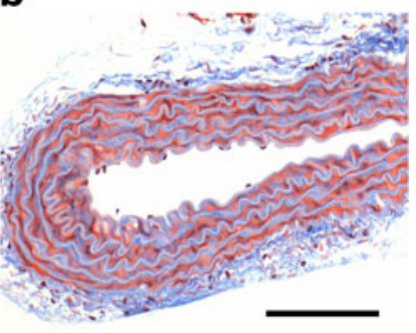

C

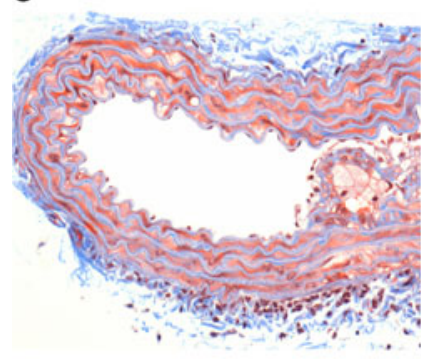

d
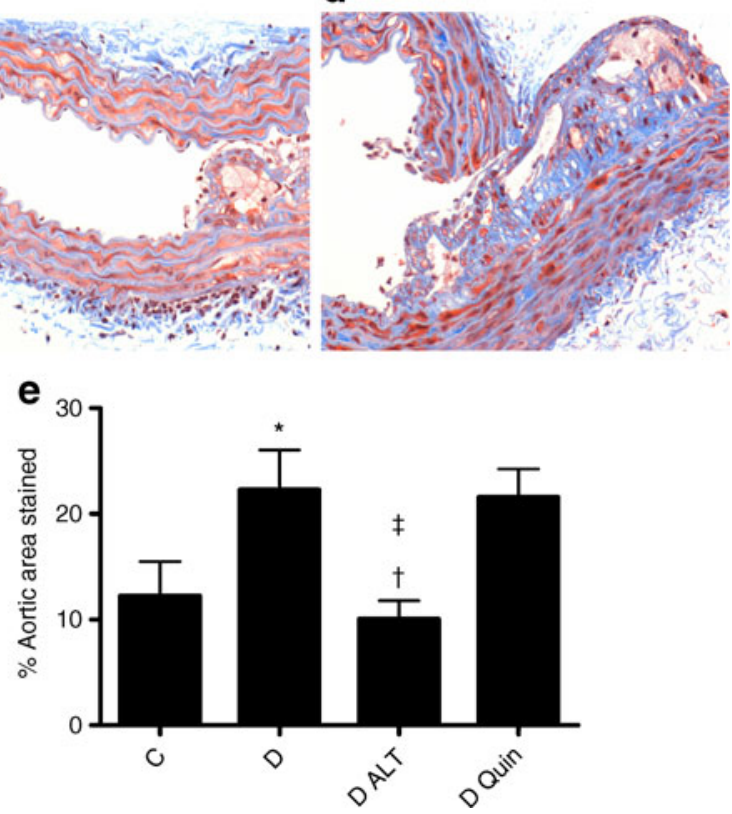

Fig. 6 a-d Photomicrographs of trichrome stained mouse aorta: untreated diabetic mice (a); untreated non-diabetic control mice (b); diabetic mice+alagebrium, $1 \mathrm{mg} / \mathrm{kg}$, for weeks 10-20 (c); diabetic mice + quinapril $30 \mathrm{mg} / \mathrm{kg}$ for weeks 10-20 (d). e Digital quantification of collagen (blue) staining in the whole aorta ( $n=4$ 8 per group). Scale bar, $100 \mu \mathrm{m} .{ }^{*} p<0.05$ vs control mice; ${ }^{\dagger} p<0.05$ vs diabetic mice with delayed intervention with quinapril; ${ }^{\star} p<0.05$ vs diabetic mice. $\mathrm{C}$, non-diabetic control mice; $\mathrm{D}$, diabetic mice; D ALT, diabetic mice with delayed intervention with alagebrium, $1 \mathrm{mg} / \mathrm{kg} ; \mathrm{D}$ Quin, diabetic mice with delayed intervention with quinapril, $30 \mathrm{mg} / \mathrm{kg}$

directly after the induction of diabetes [8]. The current study investigated the effect of a delayed intervention strategy using two separate anti-AGE compounds, alagebrium and pyridoxamine, in a model where diabetes-associated atherosclerosis was already established. We also investigated the effects of the ACE inhibitor, quinapril, which has been shown to have anti-atherosclerotic effects when given as a preventive therapy in this animal model [12].

At the time of each intervention (commencing 10 weeks after the induction of diabetes), diabetic Apoe ${ }^{-/-}$mice have already accumulated plaque covering $5-10 \%$ of the total aortic surface area. In addition, the vessel wall already contains increased amounts of AGEs. Despite this, we have shown for the first time that delayed intervention treatment in diabetes with the anti-AGE agents alagebrium and pyridoxamine can attenuate atherosclerotic plaque formation in diabetic mice with established atherosclerosis. Furthermore, the anti-atherosclerotic effects of alagebrium were comparable with those observed with the ACE inhibitor quinapril. These anti-atherosclerotic effects using two distinct anti-AGE compounds suggest that even when given as a delayed intervention, anti-AGE therapies may present a new potential regimen for the attenuation of progression of diabetes-associated atherosclerosis.

The mechanism(s) by which alagebrium and pyridoxamine exert their anti-atherosclerotic effects in vivo remains to be fully established. While both interventions attenuated the further progression of established diabetes-associated atherosclerosis, none of the interventions regressed plaque development or associated markers of inflammation and fibrosis to levels less than those observed at 10 weeks of diabetes, the time-point when the treatment was started. Although both alagebrium and pyridoxamine have been reported to be able to cleave covalent cross-linked compounds in vitro [8, 13-15], we demonstrated that vascular AGE and RAGE protein levels were not reduced by the delayed treatment with alagebrium. Consequently, their anti-atherosclerotic actions in our model appear to be associated with inhibiting AGE formation, rather than breaking pre-formed AGE cross-links. Certainly, alagebrium was able to reduce the accumulation of circulating methylglyoxal and albumin fluorescence, a biomarker of AGE modification [16]. However, other vasculoprotective actions have also been attributed to alagebrium, including inhibition of RAGE-dependent protein kinase $\mathrm{C}$ signalling [17] and antioxidant actions. In our study, delayed intervention with alagebrium was associated with a significant attenuation of oxidative stress in the vascular wall, as measured by accumulation of nitrotyrosine residues. By contrast, it has previously been found that alagebrium, $10 \mathrm{mg} \mathrm{kg}^{-1}$ per day ${ }^{-1}$, did not decrease renal nitrotyrosine staining in the kidney of diabetic rats when given as a delayed intervention [18].

RAS blockade with an ACE inhibitor or an angiotensin II receptor blocker is considered to be the first-line treatment in the prevention of diabetic end-organ complications [19, 20]. We have previously shown that the RAS plays an important role in the development of diabetes-associated atherosclerosis [21]. The current study is the first to demonstrate that delayed intervention therapy with quinapril attenuates the development of diabetes-associated atherosclerosis in established diabetes. This was accompanied by attenuation of Agtrla and Agtr2 expression in the diabetic aorta, as well as expression of genes for pro-inflammatory mediators such as VCAM1 and IL-1 $\beta$. This supports the hypothesis that both the RAS and AGEs act to progress diabetes-associated atherosclerosis [4, 22].

Whilst the blood pressure-lowering effects of quinapril undoubtedly contributed to the anti-atherosclerotic effect of 
this delayed therapy, previously our group have demonstrated that blood pressure reduction alone is not sufficient to account for the reduction of diabetes-associated atherosclerosis in this model [21]. Previously, we have found that this dose of quinapril reduced aortic atherosclerosis and nitrotyrosine staining in the diabetic $A p o e^{-/-}$when used as a preventive (20 week) therapy [12]. The current study found that delayed intervention therapy with quinapril also decreased aortic nitrotyrosine levels. This, together with decreases in plasma AGEs in diabetic animals, suggests that quinapril exerts both anti-AGE and anti-oxidant effects in established atherosclerosis.

In summary, the present studies show that delayed intervention with two different anti-AGE compounds retarded but did not completely arrest the continued development of established diabetes-associated atherosclerosis. These effects were comparable with those achieved by ACE inhibition. This re-affirms the importance of ACE inhibitor treatment in established diabetes-associated atherosclerosis and provides evidence that novel treatments, such as those targeting AGEs, could be effective in combating established diabetic macrovascular disease. Although the clinical utility of AGE inhibition remains to be firmly established, these findings suggest that treatments that target the AGE-RAGE pathway may be effective in attenuating diabetes-associated atherosclerosis in patients with pre-existing macrovascular disease.

Acknowledgements We offer grateful thanks for the technical assistance provided by D. Samijono. A. M. D. Watson is currently supported by the NHMRC Australian Biomedical Fellowship (472698). K. J. A. Jandeleit-Dahm, T. J. Allen and M. C. Thomas are supported by NHMRC Senior Research Fellowships. A. SoroPaavonen was supported by Finnish Cultural Foundation, Maud Kuistila Foundation and The Finnish Diabetes Association. This study was also supported by an NHMRC project grant. M. C. Thomas is supported by the KHA Bootle bequest.

Duality of interest The authors declare that there is no duality of interest associated with this manuscript.

\section{References}

1. Goldin A, Beckman JA, Schmidt AM, Creager MA (2006) Advanced glycation end products: sparking the development of diabetic vascular injury. Circulation 114:597-605

2. Thornalley PJ, Langborg A, Minhas HS (1999) Formation of glyoxal, methylglyoxal and 3-deoxyglucosone in the glycation of proteins by glucose. Biochem J 344:109-116

3. Nishikawa T, Edelstein D, Du XL et al (2000) Normalizing mitochondrial superoxide production blocks three pathways of hyperglycaemic damage. Nature 404:787-790

4. Thomas MC, Tikellis C, Burns WM et al (2005) Interactions between renin angiotensin system and advanced glycation in the kidney. J Am Soc Nephrol 16:2976-2984
5. Bucciarelli LG, Wendt T, Qu W et al (2002) RAGE blockade stabilizes established atherosclerosis in diabetic apolipoprotein Enull mice. Circulation 106:2827-2835

6. Calkin AC, Forbes JM, Smith CM et al (2005) Rosiglitazone attenuates atherosclerosis in a model of insulin insufficiency independent of its metabolic effects. Arterioscler Thromb Vasc Biol 25:1903-1909

7. Candido R, Jandeleit-Dahm KA, Cao Z et al (2002) Prevention of accelerated atherosclerosis by angiotensin-converting enzyme inhibition in diabetic apolipoprotein E-deficient mice. Circulation 106:246-253

8. Forbes JM, Yee LT, Thallas V et al (2004) Advanced glycation end product interventions reduce diabetes-accelerated atherosclerosis. Diabetes 53:1813-1823

9. Cefalu WT, Wang ZQ, Bell-Farrow A, Kiger FD, Izlar C (1994) Glycohemoglobin measured by automated affinity HPLC correlates with both short-term and long-term antecedent glycemia. Clin Chem 40:1317-1321

10. Soro-Paavonen A, Watson AMD, Li J et al (2008) Receptor for advanced glycation end products (RAGE) deficiency attenuates the development of atherosclerosis in diabetes. Diabetes 57:24612469

11. Thomas MC, Tsalamandris C, MacIsaac R et al (2004) Lowmolecular-weight AGEs are associated with GFR and anemia in patients with type 2 diabetes. Kidney Int 66:1167-1172

12. Watson AMD, Li J, Schumacher C et al (2010) The endothelin receptor antagonist avosentan ameliorates nephropathy and atherosclerosis in diabetic apolipoprotein E knockout mice. Diabetologia 53:192-203

13. Thomas MC, Baynes JW, Thorpe SR, Cooper ME (2005) The role of AGEs and AGE inhibitors in diabetic cardiovascular disease. Curr Drug Targets 6:453-474

14. Cooper ME (2004) Importance of advanced glycation end products in diabetes-associated cardiovascular and renal disease. Am J Hypertens 17:31S-38S

15. Metz TO, Alderson NL, Chachich ME, Thorpe SR, Baynes JW (2003) Pyridoxamine traps intermediates in lipid peroxidation reactions in vivo: evidence on the role of lipids in chemical modification of protein and development of diabetic complications. J Biol Chem 278:42012-42019

16. Shaklai N, Garlick RL, Bunn HF (1984) Nonenzymatic glycosylation of human serum albumin alters its conformation and function. J Biol Chem 259:3812-3817

17. Thallas-Bonke V, Lindschau C, Rizkalla B et al (2004) Attenuation of extracellular matrix accumulation in diabetic nephropathy by the advanced glycation end product cross-link breaker ALT-711 via a protein kinase C-alpha-dependent pathway. Diabetes 53:2921-2930

18. Forbes JM, Thallas V, Thomas MC et al (2003) The breakdown of preexisting advanced glycation end products is associated with reduced renal fibrosis in experimental diabetes. FASEB J 17:1762-1764

19. Cooper ME, Johnston CI (2000) Optimizing treatment of hypertension in patients with diabetes. JAMA 283:3177-3179

20. Jandeleit-Dahm K, Lassila M, Davis BJ et al (2005) Antiatherosclerotic and renoprotective effects of combined angiotensinconverting enzyme and neutral endopeptidase inhibition in diabetic apolipoprotein E-knockout mice. J Hypertens 23:2071-2082

21. Candido R, Allen TJ, Lassila M et al (2004) Irbesartan but not amlodipine suppresses diabetes-associated atherosclerosis. Circulation 109:1536-1542

22. Koitka A, Cao Z, Koh P et al (2010) Angiotensin II subtype 2 receptor blockade and deficiency attenuate the development of atherosclerosis in an apolipoprotein E-deficient mouse model of diabetes. Diabetologia 53:584-592 